\title{
A DESESTRUTURAÇÃO FAMILIAR E O ADOLESCENTE EM CONFLITO COM A LEI: PONTOS E CONTRAPONTOS
}

\section{THE FAMILY'S PROBLEM AND TEENAGER IN CONFLICT WITH THE LAW: POINTS AND COUNTERPOINTS}

\begin{abstract}
VANISSE MONTEIRO CAMPOS
Bacharel em Direito, pela Faculdade de Ciências Jurídicas e Sociais Aplicadas do Araguaia - FACISA. Pós Graduação (em andamento) em Direito Civil e Processo Civil. Pesquisadora do Núcleo de Iniciação Científica, na linha - Direitos Humanos e Cidadania, da FACISA. anissecampos25@yahoo.com.br
\end{abstract}

GISELE SILVA LIRA DE RESENDE Doutora em Educação, com Pós doutorado em Educação e Saúde (UFMT). Bacharel em Serviço Social e Licenciada em Pedagogia. Professora do Programa de Pós-graduação em Direito e em Educação da Faculdade de Ciências Jurídicas e Sociais Aplicadas do Araguaia. Professora nos Cursos de Direito e de Pedagogia. Professora Pesquisadora do Núcleo de Iniciação Científica, na linha - Direitos Humanos e Cidadania, da FACISA. giselelira@hotmail.com

\section{RESUMO}

A discussão sobre adolescentes que se envolvem em ações violentas tem sido considerada um problema social de grandes dimensões, seja como vítimas, seja como autores. Nessa conjuntura, esta pesquisa, realizada na área de Direitos Humanos, tem por objetivo maior compreender quais elementos da dinâmica familiar de adolescentes em conflito com a lei, que estão cumprindo medida de privação de liberdade, no sistema socioeducativo, do município de Barra do Garças - MT, contribuíram para que estes ingressassem no mundo da infração. Trata-se de uma a pesquisa exploratória, de abordagem qualitativa, que analisa, de modo estreito, a dinâmica familiar desses internos. Utilizou-se em discussão teórica, obras de Kozen, Dias, Tepedino, Estatuto da criança e do Adolescente, dentre outras. Já a pesquisa de campo foi realizada na instituição supracitada. Conclui-se que o ambiente familiar pode influenciar os adolescentes à prática de atos ilícitos.

Palavras-chave: Adolescentes em Conflitos com a Lei; Dinâmica Familiar; Medida de Privação de Liberdade.

\begin{abstract}
The discussion about teenagers who engage in violent actions have been considered a large social problem, whether as victims or as perpetrators. In this context, this research, carried out in the area of Human Rights aims higher, understand which elements of the family dynamic of adolescents in conflict with the law, which are a measure of deprivation of liberty, in the SocioEducational System, the municipality of Barra do Garças-MT, contributed to these enter in the world of infraction. This is an exploratory research, qualitative approach, which analyses, so narrow, the family dynamics of these interns. It was used in theoretical discussion, works of Kozen, Dias, Tepedino, Statute of children and adolescents, among others. Already the field research was carried out in the aforementioned institution. It is concluded that the home environment can influence the teenager to commit unlawful acts.
\end{abstract}

Keywords: Adolescents in Conflict with the Law; Family Dynamics; Deprivation Measure of Freedom. 


\section{SUMÁRIO}

INTRODUÇAO; 1 A CONSTRUÇÃO HISTÓRICA DA FAMÍLIA; 2 A FAMILÍA COMO NÚCLEO CENTRAL DO ORDENAMENTO JURIDICO BRASILEIRO; 3 FAMÍLIA, SOCIEDADE E ESTADO: ALGUMAS CONSIDERAÇÕES; 4 ANÁLISE E DISCUSSÃO DA PESQUISA; 4.1 Qualificação dos Sujeitos da Pesquisa; 4.2 Sobre os Resultados da Pesquisa; 4.3 Dos Profissionais que atuam no Sistema Socioeducativo; CONCLUSÃO; REFERÊNCIAS.

\section{INTRODUÇÃO}

A discussão sobre adolescentes que se envolvem em ações violentas tem sido tema constante, e hoje, é considerada um problema social de grandes dimensões, seja como vítimas, seja como autores. Os meios de comunicação de massa, diuturnamente, apresentam cenas horrendas protagonizadas por adolescentes que se enveredam pelo mundo infracional. Não é incomum cometerem homicídio, furtos, agirem de modo violento e banalizarem a vida: a sua e a do outro. A sociedade, nesse panorama, assiste à tudo indignada e, ao mesmo tempo, se sente impotente frente ao caos. Embora o sistema judiciário utilize mecanismos para coibir tais ações, os índices de adolescentes que cometem infrações sobem de modo assustador, o que provoca a sensação de impunidade no corpo social.

O ordenamento jurídico, por meio do Estatuto da criança e do adolescente (1990) traz em seu escopo medidas previstas tanto para os que sofrem violência, quanto para os que possuem comportamentos inadequados socialmente. Interpreta-se que, o público almejado nesse documento, está em desenvolvimento físico e psíquico. Sendo assim, precisam ser cercados de cuidados pela família, já que nela desenvolvem os primeiros aspectos sócio psicológicos. Não se está excluindo fatores individuais, mas se apontando que o "indivíduo é resultado, também, da relação com o meio onde vive"1 . Logo, a família por ser a primeira célula social da criança tem fator incisivo em sua formação.

Tal assunto é sem dúvida, amplo e complexo, não só pela extensão que compreende a instituição familiar, mas pela importância que possui na formação de uma sociedade, como base fundamental para o desenvolvimento social e democrático de uma nação. Nesse entendimento, deve contar, assim, com a proteção do Estado, como preceitua a Constituição Federal.

Com as mudanças nos padrões sociais, econômicos e políticos, bem como, com a globalização, a dinâmica familiar sofreu grande impacto. Nessa perspectiva, tais transformações

\footnotetext{
${ }^{1}$ VYGOTSKY, Lev. Semiovich. A formação social da mente. São Paulo: Martins Fontes, 1998.
} 
devem ser analisadas de forma sistemática, para que o Estado possa, então, suprir suas necessidades.

Ao se tratar do termo família, entende-se que sua composição se dá de diferentes formas: família mosaico, família homoafetiva, a família monoparental, família parental, dentre outras formações. Enfim, “a nenhuma espécie de vínculo que tenha por base o afeto se pode deixar de conferir status de família, merecedora da proteção do Estado, pois a Constituição Federal (art. $1^{\circ}$, III) consagra, em norma pétrea, o respeito à dignidade da pessoa humana" ${ }^{2}$.

Independentemente do tipo de família é comum os membros ou, a maioria deles, estarem no mercado de trabalho para prover o sustento dos filhos. Com isso, delegam a função de educar e cuidar dos seus à terceiros ou, por vezes, os deixa sozinhos. Nesse último caso, essas crianças podem ficar mais vulneráveis ao envolvimento com drogas lícitas e/ou drogas ilícitas, que, com o tempo, passam a fazer parte de suas vidas e, quando os seus responsáveis percebem, já estão tomados pelo vício, abandonam a escola e passam a ter comportamentos reprováveis. Aliás, estudos - Dallo ${ }^{3}$, Sapienza e Pedremonico ${ }^{4}$ e Scivoletto e Giusti ${ }^{5}$, apontam que o álcool é uma substância muito presente em algumas famílias, e um dos elementos que promovem a desestrutura familiar. Esta desestruturação envolve não só a violência doméstica, sob todas as formas, mas, também, a possibilidade de a criança ou adolescente se envolver com atos ilícitos, percorrendo, muitas vezes, um caminho marginal.

Compreende-se, desse modo, que é de suma importância voltar à atenção às fragilidades existentes na dinâmica familiar, com vistas a buscar a raiz do problema; tais fragilidades, em grande parte, pode conduzir à atos infracionais e, por consequência, à perturbação da ordem social.

Nesse contexto, este artigo cujo tema central é a desestruturação familiar e o adolescente em conflito com a lei, suscitou o seguinte problema: Em que medida a dinâmica

${ }^{2}$ DIAS, Maria Berenice. Manual do Direito das Famílias. 2. ed. Porto Alegre: Livraria do Advogado, 2005.

${ }^{3}$ DALLO, Luana e MARTINS, Raul Aragão Martins Uso de álcool entre adolescentes escolares: um estudopiloto. (2011) http://www.scielo.br/pdf/paideia/v21n50/05.pdf. Acesso maio 2016.

${ }^{4}$ SAPIENZA, Graziela e PEDREMONICO, Márcia Regina Marcondes. (2005). Risco, proteção e resiliência no desenvolvimento da criança e do adolescente [Versão eletrônica]. Psicologia em Estudo, 10(2), 209-216. Recuperado em 19 setembro 2009, de http://www.scielo.br/pdf/pe/v10n2/v10n2a07.pdf. Acesso maio. 2016.

${ }^{5}$ SCIVOLETTO, Sandra, e GIUSTI, L. S. (2007). Fatores protetores e de risco associados ao uso de drogas na adolescência [Versão eletrônica]. Álcool e drogas sem distorção. http://apps.einstein.br/alcooledrogas/novosite/atualizacoes/ac_131.htm Acesso maio. 2016 
familiar de adolescentes em conflito com a lei podem estar associadas às práticas de ações infracionais?

Acredita-se que famílias desestruturadas, possuam maior probabilidade de ter adolescentes que se envolvam precocemente em ações ilícitas, em virtude das situações vivenciadas que, por sua vez, podem interferir em sua formação de personalidade e de conduta moral.

Desta feita, por meio de casos plurais, buscou-se compreender quais elementos da dinâmica da família de adolescentes em conflito com a lei, que estão cumprindo medida de internação, no centro socioeducativo, do município de Barra do Garças - MT, contribuíram para que estes ingressassem no mundo da delinquência.

Frente as interrogativas lançadas nesse estudo e a forma de abordagem do problema, entendeu-se ser uma pesquisa de natureza básica, de objetivo exploratório, com a finalidade de identificar comportamentos do convívio familiar dos adolescentes que enfrentam problemas com o judiciário em Barra do Garças- MT, esclarecendo, por consequência, a razão de tal conduta.

Nesse contexto, a abordagem qualitativa, se fez mais adequada, por permitir interpretar os significados das vivências em família.

Para tanto, além da pesquisa bibliográfica em obras que abordam a temática, adotouse, em pesquisa de campo, como técnica de coleta de dados, o questionário estruturado com os referidos agentes infratores e seus familiares, bem como a entrevista semiestruturada com profissionais que atuam nesses casos: psicólogo e assistente social.

Com vistas a estear a pesquisa bibliográfica, utilizou-se obras de Kozen ${ }^{6}$, Dias ${ }^{7}$, Bodin de Moraes $^{8}$, Maluf $^{9}$, Tepedino ${ }^{10}$, Naplava e Dietrich ${ }^{11}$ e o Estatuto da Criança e do Adolescente ${ }^{12}$ dentre outras, não menos importantes.

\footnotetext{
${ }^{6}$ KONZEN, Afonso Armando. Pertinência socioeducativa: reflexões sobre a natureza jurídica das medidas. Porto Alegre: Livraria do Advogado, 2005.

${ }^{7}$ DIAS, Maria Berenice. Manual do Direito das Famílias. 2. ed. Porto Alegre: Livraria do Advogado, 2005.

${ }^{8}$ BODIN DE MORAES, Maria Celina. A constitucionalização do direito civil e seus efeitos sobre a responsabilidade. Direito, Estado e Sociedade - v.9 - n.29 - p 233 a 258 - jul/dez 2006. Disponível em http://www.egov.ufsc.br/portal/sites/default/files/a_constitucionalizacao_do_direito_civil_e_seus.pdf >. Acesso em maio 2016.

${ }^{9}$ MALUF, Adriana Caldas do Rego Freitas Dabus. Novas modalidades de Família na Pós Modernidade. São Paulo: Atlas, 2010.

${ }^{10}$ TEPEDINO, Gustavo. A disciplina da guarda e da autoridade parental na ordem civil-constitucional. In: Temas de direito civil - tomo II. Rio de Janeiro: Renovar, 2006, 176.
} 
Discute-se, ao longo desse artigo, a construção histórica da família, indicando, a cada tempo, sua função social e a influência que têm na formação de personalidade, de caráter e de vínculos afetivos para, em seguida, analisar a família, não só a partir de uma visão antropocêntrica, mas também, sob a ótica constitucional, designando-a como base social, ao mesmo tempo que aponta para a responsabilidade do Estado, para com esta instituição.

Sem sombra de dúvida cabe, aqui, uma discussão mais profícua, com fito de refletir sobre o papel que a família possui na vida dos filhos, em sua formação, para que este não se envolva em atos ilícitos e, por consequência, se torne um adulto criminoso. Por derradeiro, realiza-se uma discussão sobre os dados da pesquisa de campo, realizada no Centro Socioeducativo, localizado no município de Barra do Garças.

Não se pretende exaurir o tema, mas sim, a partir dos resultados apresentados, oferecer subsídios que possam conduzir à reflexão acerca de como os novos padrões sociais de consumo e de educação, dentro do ambiente familiar, podem ocasionar situações que levam à instância do poder judiciário.

\section{A CONSTRUÇÃO HISTÓRICA DA FAMÍLIA}

Acredita-se que o agrupamento, hoje, conhecido como família, não era embasado nas relações individuais, ou seja, na monogamia. A vida sexual de algumas tribos era intensa e não haviam parceiros fixos.

Com o passar do tempo e com o desenvolvimento das civilizações, o homem se tornou responsável pelo suprimento das necessidades existentes dentro do âmbito familiar. Era ele quem saia para a caça, para pesca e para guerrear em defesa da família, enquanto a mulher e os filhos cuidavam dos afazeres domésticos. Criou-se de forma natural uma (co) dependência entre o homem e o restante dos seus, oportunizando, dessa forma, a autoridade paternal soberana no meio doméstico.

\footnotetext{
${ }^{11}$ NAPLAVA, Thomas; OBERWITTLER, Dietrich. Factores familiares e delinquência juvenil: resultados da investigação sociológica na Alemanha. In: FONSECA, António Castro. Comportamento antissocial e família. Coimbra: Almedina, 2002.

${ }_{12}$ BRASIL. Lei $n^{\circ} 8069$ de 13 de Julho de 1990. Dispõe sobre o Estatuto da Criança e do Adolescentes e dá outras providencias. Brasília, DF, de 13 Jul. de 1990, Disponível em: <http://www.planalto.gov.br/ccivil_03/leis//8069.htm> Acesso em: 18 de Jul. de 2014.
} 
$\mathrm{Na}$ concepção dos antigos gregos e romanos, a esposa, os filhos e os servos eram propriedade do pater famílias. Esses eram os seus fâmulos e estavam sempre a sua disposição.

O pai possuía mais poder que o Estado no seio familiar, detinha direitos e faculdade agir por sua vontade, sendo os demais, obrigados a cumprirem suas ordens. A prole era classificada na relação dos bens do pai e poderia ser vendida como mercadoria.

Como bem aponta Caio Mário da Silva Pereira, sobre a relação familiar romana,

O pater, era ao mesmo tempo, chefe político, sacerdote e juiz. Comanda, oficiava o culto dos deuses domésticos (penates) e distribuía justiça. Exercia sobre os filhos direito de vida e de morte (ius vitae ac necis), podia impor-lhes pena corporal, vendê-los, tirar-lhes a vida. A mulher vivia in loco filiae, totalmente subordinada à autoridade marital (in manu maritari), nunca adquirindo autonomia, pois que passava da condição de filha à de esposa, sem alteração na sua capacidade; não tinha direitos próprios, era atingida por capitis demintuio pérpetua que se justificava propter sexus infirmitatem et ingnoratiam rerum forensium. Podia ser repudiada por ato unilateral do marido. ${ }^{13}$

A designação de pátrio poder que embasou as Constituições brasileiras até 1988, advém deste período, no qual o homem era o ser que possuía controle absoluto sobre a vida e sobre a morte da esposa, dos filhos e dos escravos.

Nesse sentido, observa-se que a discriminação entre gêneros ocorre desde o início da humanidade. A afeição dentro do âmbito familiar não era demonstrada. Aos filhos era destinada uma grande quantia quando casassem e, pelo menos um descendente, ficava incumbido de continuar o culto familiar aos antepassados, sob pena da desgraça se abater sobre aquele teto. As mulheres não possuíam o mesmo direito, não recebiam dote, restando, apenas, obedecer ao pai ou o marido.

A grande maioria das famílias era constituída por uma quantidade numerosa de filhos, que serviam de mão-de-obra familiar e garantiam o sustento de todo o grupo. A nomenclatura família se remete a um grupo de pessoas, acolhidas no mesmo lar, unidas pelos laços de sangue ou por afinidade. Por sua função detém um papel primordial na formação da conduta humana e social, pois, é no seio familiar que se aprende valores que servirão de base para uma vida adulta.

${ }^{13}$ PEREIRA, Caio Mário da Silva. Instituições de direito civil. Vol. V. $11^{\mathrm{a}}$ ed. Rio de Janeiro: Forense, 1997, p. 31. 
Para Rousseau ${ }^{14}$ o que une os indivíduos além da necessidade primária de manter a própria espécie é o sentimento fraternal existente em cada ser, afirma que:

A mais antiga de todas as sociedades, e a única natural, é a da família. As crianças apenas permanecem ligadas ao pai o tempo necessário que dele necessitam para a sua conservação. Assim que cesse tal necessidade, dissolve-se o laço natural. As crianças eximidas da obediência devida ao pai, o pai isento dos cuidados dos filhos, reentram todos igualmente na independência. Se continuam a permanecer unidos, já não é naturalmente, mas voluntariamente e a própria família apenas se mantém por convenção.

A partir dessa vertente, é possível observar, que a essência da instituição familiar não se modificou com o passar dos séculos, haja vista que na contemporaneidade o sentimento familiar, a afetividade ainda permanece independente de sua composição, bem como de sua dinâmica.

Apesar da complexidade, alguns doutrinadores, sob a ótica do Direito, a apresentam de modo mais stricto e outros mais lato.

Para Carlos Roberto Gonçalves "Família é que abrange todas as pessoas ligadas por um vínculo de sangue e que procedem, portanto, de um tronco ancestral comum, bem como unidas pela afinidade ou adoção”.

Venosa $^{16}$ entende que "o direito civil moderno apresenta uma definição mais restrita, considerando membros da família, as pessoas unidas pela relação conjugal ou de parentesco".

Já à luz das novas acepções de família neste século, Donizete ${ }^{17}$ coloca o termo

[...] Afeto. É em torno dessa palavra que gira o direito de família do século XXI, porque é sobre essa palavra que se constrói o conceito de família da era contemporânea. Daí que, hoje, pode-se seguramente conceituar família como o núcleo formado por pessoas que vivem em comunhão em razão de mútuo afeto. Os tradicionalmente citados como integrantes do conceito de família, na verdade compõe modelos diferentes de família, mas apenas o conceito apresentado é geral o suficiente para abranger todos os modelos que se encontra na sociedade.

14 ROUSSEAU, Jean-Jacques. Do Contrato Social França, 1762. p.11. Disponível em: <http://www.ebooksbrasil.org/adobeebook/contratosocial.pdf>Acesso em 15 de set. de 2014.

${ }^{15}$ GONÇALVES, Carlos Roberto. Direito Civil Brasileiro, Direito de Família. Vol. 06. $9^{\text {a }}$ ed. São Paulo: Saraiva, 2012.

${ }^{16}$ VENOSA, Silvio de Salvo. Direito civil: direito de família. $9^{\text {a }}$ ed. Vol. 06 São Paulo: Atlas, 2009.

${ }^{17}$ DONIZETTI, Elpídio; QUINTELLA, Felipe. Curso didático de direito civil. 3.ed. São Paulo: Atlas, 2014. 
Como é possível perceber, o conceito se modificou ao longo dos tempos, uma vez que, a família era, apenas, reconhecida pelos laços sanguíneos; hoje ela se define pela afinidade ou pela adoção, que seria uma afinidade outorgada por lei. ${ }^{18}$

E ainda “[...] ao ser reconhecida como família a união estável, ou seja, a união entre duas pessoas constituídas pelo laço da afetividade, houve o alargamento conceitual do que é família. Deixou de ser casamento, sexo e reprodução para ser identificada como o fruto de um elo de afetividade". ${ }^{19}$

Tal ideia é corroborada por Maluf ${ }^{20}$, que concebe “[...] a família é originariamente o lugar onde o homem se encontra inserido por nascimento ou adoção e nela desenvolve, através das experiências vividas, sua personalidade e seu caráter".

Nessa direção, o núcleo da família contemporânea foi-se delineando paulatinamente, a partir da mudança dos costumes, dos valores, da própria revolução da sociedade, bem como da independência econômica da mulher, da igualdade e emancipação dos filhos, do divórcio, do controle de natalidade e da reciprocidade de direitos e deveres no que tange a prole.

Aqui se abre um leque maior para o conceito de família, uma vez que o afeto é o amálgama entre seus membros, independente dos laços de consanguinidade. Aliás, estudos realizados por Costa ${ }^{21}$ e Marra, apontam que a família brasileira, em grande parte é constituída por mães, sejam elas solteiras ou divorciadas. Essa mudança estrutural provocou alterações não só na economia e na posição social da mulher, mas, sobretudo, na educação oferecida pela família.

18 DIAS, Maria Berenice. A evolução da família e seus direitos. Disponível em http://www.mariaberenice.com.br/uploads/7_a_evolu\%E7\%E3o_da_fam\%EDlia_e_seus_direitos.pdf.

Acesso em maio 2016.

${ }_{19}$ DIAS, Maria Berenice. Manual do Direito das Famílias. 2. ed. Porto Alegre: Livraria do Advogado, 2005.

19 BODIN DE MORAES, Maria Celina. A constitucionalização do direito civil e seus efeitos sobre a responsabilidade. Direito, Estado e Sociedade - v.9 - n.29 - p 233 a 258 - jul/dez 2006. Disponível em http://www.egov.ufsc.br/portal/sites/default/files/a_constitucionalizacao_do_direito_civil_e_seus.pdf >. Acesso em maio 2016.

${ }^{20}$ MALUF, Adriana Caldas do Rego Freitas Dabus. Novas modalidades de Família na Pós Modernidade. São Paulo: Atlas, 2010.

${ }^{21}$ COSTA, Florença Ávila de Oliveira e MARRA, Marlene Magnabosco.Famílias brasileiras chefiadas por mulheres pobres e monoparentalidade feminina: risco e proteção. Rev. bras. psicodrama[online]. 2013, vol.21, n.1, pp. 141-153. $\quad$ Disponível em< http://pepsic.bvsalud.org/scielo.php?script=sci_arttext\&pid=S0104-53932013000100011. Acesso fev. 2016 


\section{A FAMILÍA COMO NÚCLEO CENTRAL DO ORDENAMENTO JURIDICO BRASILEIRO}

Em face às transformações ocorridas no século $X X$, e mais precisamente a partir de Constituição Federal de 1988, a família ganha um espaço enorme em relação às prerrogativas alcançada por esta instituição, passando a ser ponto central, no que se refere a garantias fundamentais constitucionais emanadas para a sua total proteção.

A entidade familiar ganhou tutela jurisdicional desde a Constituição Social de 1934, porém, as vantagens ganharam mais amplitude a partir da Constituição de 1988, pois as legislações anteriores traziam em seu arcabouço jurídico uma proteção de forma abstrata. Protegia-se, apenas, a família formada pelos laços da lei, deixando os demais núcleos familiares desguarnecidos, no tocante aos seus direitos.

$\mathrm{Na}$ segunda metade do século XX as instituições familiares ocidentais sofreram transformações tão elementares, que os ordenamentos jurídicos tiveram que adotar um olhar totalmente novo à luz das novas necessidades que surgiam acerca da família.

A partir do ano de 1962, com a edição do Estatuto da mulher casada (Lei $n^{\circ}$ 4.121/ $62)^{22}$, a mulher pode assumir outros papéis, para além dos limites do lar, independente da autorização do marido.

Nesse contexto, a partir dos primeiros direitos adquiridos pelo sexo feminino, a instituição familiar começa a ganhar novos moldes; a mulher passa a conquistar seu espaço perante a sociedade vai se distanciando, cada vez mais, das atividades domésticas e, por conseguinte, transfere a outras instituições, como a escola, a educação de seus.

Ademais, outras conquistas surgiram, como o advento das opções contraceptivas, na qual a mulher pôde decidir se quer ou não ter filhos, bem como o reconhecimento jurídico da igualdade dos cônjuges, que ocorreu com a edição do dispositivo $226 \S 5^{\circ}$ do texto constitucional. Para tanto, foi determinante o advento da Lei do divórcio (Lei $\left.n^{\circ} 6515 / 77\right)^{23}$, que

\footnotetext{
22 BRASIL. Lei $n^{\circ} 4121$ de 27 de Agosto de 1962. Dispõe sobre a situação Jurídica da mulher casada. Diário Oficial da República Federativa do Brasil. Brasília, DF, 27 ago. 1962. Disponível em: <http://www.planalto.gov.br/ccivil_03/leis/1950-1969/L4121.htm>. Acesso em 20 de set. de 2014.

${ }^{23}$ BRASIL. Lei $n^{\circ} 6515$ de 26 de Dezembro de 1977. Regula os casos de dissolução da sociedade conjugal e do casamento, seus efeitos e respectivos processos, e dá outras providências. Brasília, DF, 26 de Dez.
} 
ao admitir a dissolução do casamento favoreceu por um lado a reorganização de formações familiares, pautadas em novos vínculos matrimoniais, ao mesmo tempo, em que deu visibilidade às estáveis relações conjugais, em substituição ao, pejorativo, concubinato.

Desse modo, verifica-se que o modelo institucionalizado de família, previsto no Código Civil de 1916, já não mais atendia os anseios sociais. Logo, foi necessário oferecer proteção jurídica às novas formações de família. A multissecular tutela exclusiva da família, fundada no casamento indissolúvel, deu lugar à proteção de relações familiares instrumentais.

Constata-se, na história constitucional brasileira, que pouco se protegeu as relações familiares, principalmente, no que tange à proteção dos filhos nascidos fora do casamento. Felizmente, nos dias atuais, essa situação já não é admitida e, independente da relação existente entre os genitores, possuem proteção legal e the é concedido direitos iguais.

A partir da promulgação da Constituição Federal de1988 houve uma ruptura no conceito da família tradicional patriarcal, e surgiu uma visão mais ampla e acolhedora. A partir do artigo $5^{\circ}$ da Constituição Federal e o Princípio da Dignidade da Pessoa Humana a instituição familiar ganha novas prerrogativas que antes não era contemplada. Desta feita, o Estado fica incumbido de proporcionar à seus entes condições propícias à efetiva igualdade para todos os tipos de núcleo familiar.

Descerrou-se um novo prisma acerca das outras modalidades de família, a exemplo, as que não eram compostas pelos vínculos jurídicos: família monoparental, a família homoafetiva, dentre outras modalidades de núcleos familiares que vieram se formando ao longo do desenvolvimento social, garantindo, assim, os direitos antes alcançados, apenas, pelas famílias elencadas no ordenamento jurídico.

\section{FAMÍLIA, SOCIEDADE E ESTADO: ALGUMAS CONSIDERAÇÕES}

Ao longo da história a família desempenhou diversas funções em vários segmentos da sociedade como na política, religião, economia, cultura, entre outras.

No plano sociocultural, a família se destaca como a primeira célula de socialização dos seus indivíduos. Como àquela que além de atender às necessidades basilares do ser humano,

de 1977. Disponível em: <http://www.planalto.gov.br/ccivil_03/leis/l6515.htm>. Acesso em: 20 de set. de 2014. 
possui, também, o dever de oferecer parâmetros para a inserção social de sua prole, em se tratando de comportamentos, hábitos, usos, costumes, crenças e tradições, com vistas a prepará-los para a vida adulta em sociedade.

Tais ideias são corroboradas por Campos $^{24}$, quando externa que “a função primordial da família, que constitui a razão de ser, é a assistência espiritual, psicológica, material, moral e de socialização de seus membros, fazendo desta, uma instituição social imprescindível, em face das funções sociais que desempenha".

Entende-se aqui que o autor acredita que dentre os encargos atribuídos à instituição familiar, a de preparar seus membros para a vida em sociedade, talvez, seja a mais importante, tendo em conta que, se esse processo for burlado, a sociedade poderá entrar em colapso.

Com a Constituição Federal de 1988, o ser humano passa a ser o cerne; entende-se que a dignidade da pessoa humana é o que se tem de maior valor, e o que se deve preservar a todo custo, em todas as esferas sociais.

Nesse diapasão, Barbosa salienta que

[...] o ser humano passa a ocupar o centro do ordenamento e consolidando-se a dignidade da pessoa humana como valor maior, cujo respeito se impõe como valor estrutural da República, a determinar a revisão e adaptação de todo sistema jurídico. Inicia-se, [...], a determinada "constitucionalização do direito civil", que se fez forte no que concerne à família, à medida que se lhe reconhece o papel de núcleo natural para pleno desenvolvimento das potencialidades de seus integrantes. (BARBOZA, 2001, p. 18-30) ) $^{25}$

Dessa forma, o artigo 227 da Carta Magna distribui, solidariamente, entre família, sociedade e Estado a obrigação de combater, incessantemente, qualquer tipo de negligência, violência e exploração e, ao mesmo tempo, bem como propiciar à criança e adolescente, dentre outras coisas, à dignidade, a convivência familiar e os instrumentos necessários à convivência social, denominados, pela Sociologia, de processo de socialização.

O processo de socialização de um indivíduo pressupõe duas fases: primária e secundária. $\mathrm{Na}$ primeira fase o indivíduo recebe as primeiras instruções sobre hábitos característicos do seu grupo social, recebe as primeiras lições de comportamento, cuja finalidade é prepará-lo para

\footnotetext{
${ }^{24}$ CAMPOS, Diogo Leite de. A nova família. In: TEIXEIRA, Sávio de Figueiredo (Org.) Direitos da família e do menos. 3 ed. Belo Horizonte: Del Rey, 1993. P. 22-25.

${ }^{25}$ BARBOZA, Heloisa Helena. O direito de família no projeto de código civil: considerações sobre 0 “direito pessoal”. Revista Brasileira de Direito de Família, Porto Alegre, n. 11, out/dez 2001, p.18-30.
} 
vida social. Esses ensinamentos são importantíssimos na vida de qualquer indivíduo, pois será utilizado em outro estágio da vida social. Já a fase secundária ocorre em outros grupos sociais: igreja, escola, amigos, etc.

Em meio as essas fases de socialização, o ser humano se desenvolve psicologicamente, culturalmente e tem sua formação moral a partir dos valores apreendidos, para, então, se adequar aos parâmetros estabelecidos pela sociedade, na qual faz parte.

Nesse sentido, quando esse processo não é realizado de modo adequado, seja por parte da família, seja por parte da sociedade, os reflexos poderão incidir na esfera judicial, cabendo a este segmento, o árduo processo de ressocialização de adolescentes, que entraram em conflito com a lei.

Diante disso, há que se preocupar, de modo incisivo, com as gerações futuras, pois, do contrário, o corpo social entrará em colapso, que, aliás, já se iniciou nos dias hodiernos. Logo, faz-se necessário atenção máxima às famílias, para que estas tenham condições de educar sua prole para serem pessoas de bem e de caráter.

O que se observa contemporaneamente, é um grande número de lares desestruturados que deixam os seus à margem social, e que são privados de direitos mínimos à sua sobrevivência. Não se quer aqui justificar comportamentos inaceitáveis ou a inversão de valores que impera no país. Todavia, constata-se que, a grande maioria de adolescentes que infringem a lei são oriundos de situações adversas, sem referência de família, de valores; isto quando não seguem o exemplo dos próprio pais. É nesse momento que o Estado intervém, com intuito de ressocializálos, ocupando, assim, o lugar da autoridade parental.

A Lei $8069 / 90^{26}$ traz em seu escopo medidas protetivas e medidas socioeducativas. Estas últimas são aplicadas, somente, à adolescentes, que possuem faixa etária entre 12 e 17 anos e 11 meses e cometem ato infracional. Abaixo de 12 anos aplica-se as medidas protetivas. Em rol taxativo, a lei traz inúmeras medidas com a finalidade de chamar à reflexão sobre a ação praticada, por isso, não possuem apenas um caráter punitivo, mas, também, pedagógico. Essas medidas se apresentam sob forma de advertência, obrigação de reparar o dano, prestação de serviço à comunidade, liberdade assistida, inserção em regime de semiliberdade e internação em estabelecimento educacional. Essa última, objeto desse estudo, é a mais onerosa para o

\footnotetext{
${ }^{26}$ BRASIL. Lei no 8069 de 13 de Julho de 1990. Dispõe sobre o Estatuto da Criança e do Adolescente e dá outras providencias. Brasília, DF, de 13 Jul. de 1990, Disponível em: <http://www.planalto.gov.br/ccivil_03/leis/l8069.htm> Acesso em: 18 de Jul. de 2014.
} 
adolescente, pois este fica abrigado em um centro de ressocialização, isolado socialmente e, nem sempre, entende essa medida como uma forma de (re) educar.

Kozen faz uma observação interessante a respeito do caráter pedagógico da medida socioeducativa de internação, quando afirma que

[...] é a crença de que há a real possibilidade da incidência de práticas pedagógicas como a principal tarefa do operador da medida socioeducativas, não só para minimizar os efeitos da perda da liberdade, mas também para alcançar ao adolescente os espaços de reflexão crítica para a percepção das causas de infração uma representação de si mesmo e do mundo do qual faz parte. Ou seja, antes de se sentir unicamente prisioneiro em face do ato infracional, tenha o adolescente, gradativamente, a noção de que se encontra inserido numa comunidade educativa, onde, ainda que privado de liberdade, terá espaço para questionar, cuidar e desenvolver o seu projeto de vida, para o que não the deverá faltar apoio e ajuda (KONZEN, 2005) ${ }^{27}$.

O caráter pedagógico tem em vista proporcionar mecanismos para que, a partir da reflexão, o adolescente não reincida. Obviamente, que esse processo de educar deveria ser de responsabilidade dos pais. Nisso reside a função social da autoridade parental, "porque o princípio da dignidade humana se projeta sobre o poder-dever de promover a educação dos filhos $[\ldots] .^{28}$

Quando essa função não fica a contento, o sistema jurídico intervém tentando suprir essa falta, ao mesmo tempo em que objetiva, a inserção desse adolescente ao meio social.

Por isso, a literatura, de modo geral enfatiza a importância da família, pela responsabilidade social que the é conferida. A base familiar é o referencial do indivíduo e pode fornecer subsídios necessários para uma convivência social. Logo, é condição sine qua non identificar os fatores de fragilidade (violência doméstica, alcoolismo, etc.) dentro desta instituição, para, assim, prevenir possíveis comportamentos anti-sociais de seus membros, como é o caso da prática de atos ilícitos, pois, como já se afirmou, tais atitudes podem estar relacionadas à dinâmica da família a que pertence.

\footnotetext{
27 KONZEN, Afonso Armando. Pertinência socioeducativa: reflexões sobre a natureza jurídica das medidas. Porto Alegre: Livraria do Advogado, 2005.

${ }^{28}$ TEPEDINO, Gustavo, O Código Civil e o direito civil-constitucional. In: Temas de Direito Civil, t. II. Rio de Janeiro: Renovar, 2006. Op. cit., p. 176
} 


\section{ANÁLISE E DISCUSSÃO DA PESQUISA}

As inúmeras dificuldades colocadas às famílias brasileiras, por conta da perversa desigualdade social, muitas vezes, impede que crianças e adolescentes tenham crescimento saudável e digno. Por outro lado, as políticas sociais ineficazes não atendem ao mínimo exigido e, podem resultar em situações de violência, de negligência, de desarmonia, dentre outras coisas, no seio familiar e, por consequência, pode influenciar negativamente na formação das crianças e dos adolescentes. É nesse sentido processo cíclico que eclode a relação família, Estado e sociedade.

O abandono material e moral, a omissão ou a negligência dos pais, da sociedade e do Estado são as primeiras formas de lesão e/ou violação dos iniciais direitos de qualquer recém-nascido. É a partir delas que se projetam as demais, uma vez que à medida que a criança aumenta sua idade, ao lado das tímidas e insuficientes ações governamentais, diversificam-se, de forma crescente, as ações e os mecanismos de lesão dos novos direitos. (SOUZA, 2008, p.75) ${ }^{29}$.

Não está se querendo justificar situações de atrocidades cometidas por pais e/ou filhos que a mídia, constantemente, expõe. Busca-se aqui afirmar que as adversidades acima apontadas, que ferem a dignidade humana, podem direcionar à um caminho marginal, como foi possível constatar a seguir.

Em outubro de 2014 foi realizada uma pesquisa de campo no sistema socioeducativo, da cidade de Barra do Garças, na qual se encontra os adolescentes em regime de internação. Foram utilizados questionários estruturados à 13 (treze) adolescentes que lá se encontram, bem como foi realizada uma entrevista semiestruturada com o psicólogo e com a assistente social dessa instituição, com a finalidade de evidenciar os pontos de interesse da matéria em tela, ao mesmo tempo em que foi possível dar liberdade de expressão aos participantes. A natureza interativa da técnica adotada possibilitou aproximação do significado atribuído por esses sujeitos à situação em estudo.

Após a assinatura do termo de esclarecimento livre e consentido pelos participantes da pesquisa, os questionários estruturados foram aplicados aos adolescentes, com a finalidade de se

${ }^{29}$ SOUZA, Jadir Ciqueira de. A afetividade dos direitos da criança e do adolescente. São Paulo: Editora Pillares, 2008. 
obter informações sobre a relação estabelecida entre os reeducandos e a dinâmica familiar a que pertencem.

O formulário preenchido por eles continha: 1) Pseudônimo 2) natureza ato infracional praticado 3) Faixa etária 4) Cor de pele 5) o grau de escolaridade 6) Informações sobre com quem convivia antes da internação 7) Utilização de droga ilícita 8) Reincidência 9) Participação em programa de profissionalização no período de internato 10) Se algum familiar já praticou algum ato ilícito 11) Grau de parentesco 12) Fator que os conduziu à praticarem atos ilícitos.

Já a entrevista semiestruturada com o psicólogo e assistente social do Sistema Socioeducativo se fez importante, por permitir obter informações sobre o funcionamento da instituição, bem como as peculiaridades de cada caso, no que concerne à família a que pertence.

\subsection{Qualificação dos Sujeitos da Pesquisa}

A partir da análise dos dados, compreendeu-se ser importante a qualificação de cada adolescente participante da pesquisa, com vistas a perceber as similaridades na dinâmica familiar dos envolvidos neste estudo. Ressalta-se que todos os nomes são fictícios por questões éticas.

Renato é um adolescente de 16 anos, pele branca, encontra-se internado pela prática de homicídio e roubo. Possui Ensino Fundamental incompleto, morava com o pai e a madrasta, antes da internação, é usuário de maconha e cocaína, reincidente na prática de atos infracionais. Já participou de cursos no período de internação, porém, afirma que o curso não foi expressivo em sua vida profissional. Atribui a desestrutura familiar sua situação atual. Destaca que nos dois períodos em que ficou internado, a família só foi visitá-lo duas vezes.

lago, 15 anos, pele branca, se encontra internado pela prática de roubo e pequenos furtos. É usuário de crack e maconha, não concluiu o Ensino Fundamental, morava com a mãe, até ela ser presa pela pratica de tráfico de drogas e, antes de ser internado, morava com a avó. Já é reincidente e não realizou nenhum curso profissionalizante. Atribui à família, o fato de estar na situação em que se encontra.

Kauê, 15 anos, indígena, está internado pela pratica de roubo, possui Ensino Fundamental incompleto, usa todos os tipos de drogas. Morava com a avó antes de ser 
internado, é reincidente e já fez curso profissionalizante. Não tem familiares envolvidos com atos ilícitos, atribui às drogas e ao consumismo material exacerbado, o fato de estar em conflito com a lei.

Carlos é um adolescente de 16 anos, pardo, não concluiu o Ensino Fundamental, está internado pela pratica de roubo. Morava com pai e mãe antes de ser internado, usa todos os tipos de drogas, não é reincidente, não fez curso no período de internação, não tem familiares envolvidos com atos ilícitos, e atribui às más amizades e às drogas, sua condição atual.

André possui 16 anos, de pele parda, que está internado pela prática de roubo e furto; não concluiu o Ensino Fundamental. Morava com a mãe antes da internação, é usuário de todo tipo de droga, não é reincidente, não fez curso profissionalizante no período de internato. A família não tem envolvimento com atos ilícitos e atribui às drogas, às más companhias e a falta da figura paterna, o fato de estar hoje privado de liberdade.

Eduardo, 16 anos, pele branca, está internado pela prática de homicídio e roubo. Não concluiu o Ensino Fundamental, morava com os pais antes da internação, usa todos os tipos de drogas, é reincidente e já participou de curso profissionalizante. Não possui familiares que praticaram atos ilícitos e atribui as drogas e más companhias, o fato de ter se envolvido em atos infracionais.

Jonas é um adolescente com 16 anos de pele parda, não concluiu o ensino fundamental, está internado pela prática de homicídio, roubo e furto, os pais são separados, é usuário de todo tipo de droga ilícita, é reincidente e nunca fez curso profissionalizante. Possui familiares que já praticaram atos ilícitos e atribui à família, o fato de estar na situação em que se encontra.

Luiz,17 anos, cor parda, encontra-se internado pela pratica de roubo e não concluiu o Ensino Fundamental. Morava com a mãe e o padrasto. É usuário de todos os tipos de droga, é reincidente, não participou de nenhum curso profissionalizante no período de internato, possui familiares com registros de práticas ilícitas. Atribui a ausência do pai e questões familiares, como o fator elementar para seus atos.

Éder, 16 anos de cor branca, está internado pela prática de homicídio, possui o Ensino Fundamental completo, mora com o pai e com a madrasta, não é usuário de droga, também, não é reincidente, não fez nenhum curso profissionalizante e não tem familiares envolvidos com a prática de atos ilícitos. Atribui às questões amorosas, o fato de se encontrar em tal situação.

João é um adolescente de 17 anos e de cor branca. Está internado pela prática de roubo, não concluiu o Ensino Fundamental, morava com a mãe o irmão, o pai foi morto por 
envolvimento com o tráfico; é usuário de todos os tipos de drogas ilícitas, é reincidente, não fez curso profissionalizante e atribui às questões familiares, sua condição de interno no sistema socioeducativo.

Claudio possui 16 anos, de pele branca, não concluiu o Ensino Fundamental, está internado pela prática de roubo. Morava com a avó, é usuário de todos os tipos de drogas, é reincidente, não fez curso profissionalizante no período de internação, possui familiares envolvidos com a prática de atos ilícitos e atribui às questões familiares o fato de estar em provação de liberdade.

Leandro, 17 anos, de cor parda, que não concluiu o Ensino Fundamental. Está internado pela prática de pequenos furtos; antes da internação morava com a avó, é usuário de todos os tipos de drogas, já reincidiu, já fez curso profissionalizante e não tem familiares envolvidos com a prática de atos ilícitos. Atribui sua situação ao envolvimento com drogas e más companhia.

Lucio é um adolescente de 17 anos de cor parda, não concluiu o Ensino Fundamental, está internado pela prática de roubo e furto; antes da internação morava na rua, é usuário de todos os tipos de drogas, já reincidiu, não fez curso profissionalizante no período de internação Atribui às questões familiares o fator principal para seu envolvimento com infrações.

\subsection{Sobre os Resultados da Pesquisa}

Realizada a qualificação dos que estão cumprindo medida socioeducativa de privação de liberdade, constatou-se um número expressivo de adolescentes na faixa etária dos 16 anos, $60 \%$ dos entrevistados. Outro dado interessante foi o fato de nenhum deles terem se declarado da raça negra. Tal fato denota uma realidade distinta do que prediz o senso comum, que aponta para a população negra, como maioria de infratores. Os dados coletados registram $40 \%$ brancos, $50 \%$ pardos e $10 \%$ indígena.

No tocante a escolaridade dos reeducandos, nota-se que, em sua maioria, não concluíram o Ensino Fundamental, o que vai, totalmente, de encontro com o art. 58 do Estatuto da Criança e do Adolescente $(E C A)^{30}$, que discorre sobre o direito de acesso à educação.

Segundo Assis ${ }^{31}$,

30 BRASIL. Lei $n^{\circ} 8069$ de 13 de Julho de 1990. Dispõe sobre o Estatuto da Criança e do Adolescentes e
dá outras providencias. Brasília, DF, de 13 Jul. de 1990, Disponível em:
<http://www.planalto.gov.br/ccivil_03/leis//8069.htm> Acesso em: 18 de Jul. de 2014. 
a importância do fracasso escolar na vida dos adolescentes entrevistados, principalmente, dos infratores, deve ser vista sob diversos ângulos. Os jovens com tais problemas familiares tendem a ir mal na escola; o mau desempenho estimula a ampliação do grupo de amigos, em muitos casos, ligados ao mundo infracional, e, também, contribui para o sentimento de fracasso na vida e para a baixo autoestima, importantes fatores associado a delinquência.

Acredita-se que a educação se faz primordial na ressocialização dos adolescentes em conflito com a lei, e cabe ao Estado oferecer condições para tal, a fim de prepará-los para uma vida social sadia. Todavia, o que se observa é que nas instituições socioeducativas, neste caso aqui em Barra do Garças, a escolarização é oferecida, mas não é obrigatória. Esse fato gera preocupação, considerando que é um dos elementos que pode promover a mudança no comportamento dos internos.

Em relação à convivência familiar, $40 \%$ dos participantes moram com seus avós, o que reforça a tese de vários estudiosos como Dias $^{32}$ e Maluf ${ }^{33}$ de que a família nuclear, composta por pai, mãe e filhos, na sociedade contemporânea, não é uniforme, dando lugar à outras modalidades de família.

Já acerca das drogas ilícitas, 90\% fazem uso dos mais variados tipos de substancias, como por exemplo, maconha, cocaína e crack; esta última substância é utilizada por todos.

Nesta fase, como mencionado anteriormente, esse público fica mais vulneráveis e pode se envolver com entorpecentes.

A droga aparece na adolescência, muitas vezes, como uma ponte que permite o estabelecimento de laços sociais, propiciando ao indivíduo o pertencimento a um determinado grupo de iguais, ao tempo que buscam novos ideais e novos vínculos, diferentes do seu grupo familiar de origem. ${ }^{34}$

Importante salientar que os sujeitos pesquisados, em sua maioria, atribuíram fator determinante para estarem nesta situação, às más companhias, as amizades negativas.

${ }^{31}$ ASSIS, Simone Gonçalves de; CONSTANTINO, Patrícia. Filhas do Mundo: Infração Feminina no Rio de Janeiro, $1^{\text {a }}$ ed. Rio de Janeiro: Fio Cruz, 2001.

${ }^{32}$ DIAS, Maria Berenice. A evolução da família e seus direitos. Disponível em http://www.mariaberenice.com.br/uploads/7_a_evolu\%E7\%E3o_da_fam\%EDlia_e_seus_direitos.pdf.

Acesso em maio 2016.

${ }^{33}$ MALUF, Adriana Caldas do Rego Freitas Dabus. Novas modalidades de Família na Pós Modernidade. São Paulo: Atlas, 2010

${ }^{34}$ FILHO, Antônio Nery; TORRES, Inês Maria Antunes Paes (orgs.). Drogas, isso lhe interessa? Confira Aqui. Salvador, BA: CETAD/ UFBA/ CPTT/ PMV, 2002. 
Frente a este cenário, entende-se que a droga primeiro encanta e depois apresenta uma face de sofrimento e dependência. É nessas circunstâncias que os vínculos familiares tendem a se afrouxarem mais ainda, e o adolescente cria uma realidade paralela àquela que é aceita socialmente. Geralmente, essa realidade é permeada pela violência, por agressões, dentre outros elementos danosos.

No que concerne ao índice de reincidência, detectou-se que cerca de $60 \%$ já reincidiram, e citam a falta de capacitação profissional como uma das causas.

Enfatiza-se que a unidade de Barra do Garças oferece curso profissionalizantes, porém, não tem representatividade frente ao mercado de trabalho; a unidade oferece cursos de artesanato, em geral. Talvez seja esse um dos motivos para que $70 \%$ dos adolescentes não tenham interesse em fazer um curso profissionalizante.

No que alude ao envolvimento dos familiares em atos ilícitos, cerca de $60 \%$ dos entrevistados admitem que algum membro da família já se envolveu em ato criminoso, ou seja, o exemplo que teve em seu lar pode ter influenciado suas ações, pois,

a crise social em que a sociedade se encontra está diretamente ligada aos valores que estão sendo perdidos e esquecidos, por aqueles a quem cabe a responsabilidade de transmiti-los e o desconhecimento daqueles que deveriam estar aprendendo, seja por ensino direto ou por observação do comportamento do outro. ${ }^{35}$

Desta feita, como já sublinhado, a importância da família em fornecer as primeiras lições, de valores morais e éticos aos seus é de suma importância, uma vez que a responsabilidade está em prepará-los para uma vida socialmente salubre.

Concebe-se que

[...] dado o seu papel central na socialização das crianças e adolescentes, a família tem sido considerada um fator decisivo no desenvolvimento da delinquência juvenil. Assim, não é por acaso que muitas teorias da delinquência juvenil se centram na estrutura familiar, na interação pais filhos e nos estilos educativos dos pais. ${ }^{36}$

\footnotetext{
${ }^{35}$ FACUNDES, Márcia Botelho. Aprendendo valores éticos. 4 ed. Belo Horizonte: Autêntica, 2001.

${ }^{36}$ NAPLAVA, Thomas; OBERWITTLER, Dietrich. Factores familiares e delinquência juvenil: resultados da investigação sociológica na Alemanha. In: FONSECA, António Castro. Comportamento antissocial e família. Coimbra: Almedina, 2002.
} 
Em se tratando dos motivos que os levaram a cometerem atos ilícitos, em sua maioria, atribuíram a diferentes fatores. Para eles, a desestruturação familiar é quase que fator unânime. Posteriormente, indicam o envolvimento com drogas, as más companhias, dentre outros.

Diante do exposto, ficou evidente, no que tange as relações familiares e o adolescente em conflito com a lei, que a estrutura familiar tem papel precípuo frente à conduta de seus membros, seja pelo exemplo, seja pela falta de estreitamento de vínculos.

\subsection{Dos Profissionais que atuam no Sistema Socioeducativo}

A entrevista com os profissionais, Assistente Social e Psicólogo, foi realizada no dia 22 de Outubro de 2014. Nessa conversa foi solicitado que discorressem, a partir de suas experiências profissionais, sobre os fatores que contribuem para que adolescentes venham a cometer atos ilícitos, bem como se a dinâmica familiar incide sobre essa situação.

Para a Assistente Social, vários são os fatores que conduzem a prática de atos ilícitos. Informou que a desestruturação familiar é um deles, assim como as políticas públicas que não funcionam, adequadamente, como saúde, educação, emprego, etc. Os adolescentes passam a ficar mais tempo na rua, se envolvem com más companhias e com drogas ilícitas. A grande maioria abandona a escola precocemente, por não considerá-la atrativa. Em contrapartida, em virtude de comportamentos inadequados e/ou dificuldades na aprendizagem são rejeitados pela própria instituição de ensino.

Sobre essa questão, é importante salientar que a escola possui uma função social de grande importância na vida do ser humano. Em um universo tão repleto de complexidade como é esse espaço, a inclusão é condição primeira para o cumprimento do exercício da cidadania.

\section{Para Resende ${ }^{37}$,}

em que se pesem os desafios da articulação entre escola e família, educadores devem se manter firmes diante dos obstáculos e devem criar mecanismos que, efetivamente, levem à construção de uma parceria entre os atores envolvidos no processo educacional, evitando, dessa forma, excluir de seu campo perceptual quem já está à margem social.

\footnotetext{
${ }^{37}$ RESENDE, Gisele Silva Lira de. A Educação a as Novas Configurações Familiares. Rev. FACISA ON LINE.

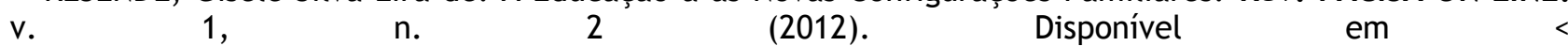
http://periodicos.faculdadecathedral.edu.br/revistafacisa/article/view/17. Acesso maio 2016.
} 
Há, ainda, para a entrevistada, a falta de profissionais especializados para acompanharem crianças e adolescentes com transtornos mentais ou de aprendizagem, o que dificulta mais e mais a sua permanência na escola, bem como a prevenção para condutas indesejáveis e não aceitas socialmente.

Outro fator de extrema relevância, segundo a entrevistada, é que crianças estão utilizando drogas cada vez mais cedo, a partir de 9 anos de idade, e não possuem atendimento, já que o órgão que pode auxiliar nesses casos, CRAS - Centro de Referência de Assistência Social, atende, somente, a partir dos 16 anos.

Nesse contexto, os pais não sabem o que fazer, o poder público, por sua vez, também, se mostra ineficaz, alegando que não pode obrigá-los a irem à escola. Como consequência desse abandono surgem transtornos de dimensões gigantescas, que se tornam problema de saúde pública, como é o caso de pessoas que se envolvem com drogas como o crack, por exemplo.

Para a assistente social, um elemento que merece atenção, é a questão da saúde. Muitos chegam ao sistema socioeducativo e nem se lembram quando foram ao médico ou ao dentista, ou seja, estão, inteiramente, vulneráveis em relação à sua saúde.

Ao dialogar com o Psicólogo, buscou-se informações sobre a questão de quais fatores podem contribuir para que os adolescentes internados chegassem à situação atual. Ele destacou que, na maioria dos casos em que atua, a desestrutura familiar é quase que uma unanimidade. Todavia, não se pode descartar a falta de amparo dos serviços públicos para com a família, de modo geral. Inclui nesse rol, a falta de fiscalização e acompanhamento às famílias em situação de risco e dos adolescentes que abandonam a escola precocemente, por parte do Conselho Tutelar. Diz que esses “meninos” chegam ao sistema socioeducativo para serem internados, sem que se tenha aplicado com eficácia a medida anterior, menos gravosa. Para ele, as medidas em meio aberto se mostram mais eficazes, no que tange a ressocialização, todavia, não há acompanhamento e a fiscalização não é adequada, por parte do Estado.

Destacou que o Sistema de Garantias dos Direitos dos Adolescentes (SGDA), vem tentando encontrar solução, no que se refere ao sistema de internação. O Psicólogo evidenciou que o Sistema Socioeducativo de Barra do Garças é referencial no Estado, pela melhor estrutura que apresenta para receber os internos; entretanto, ainda possui muitas fragilidades.

Sobre a questão dos vínculos familiares, o que inclui as visitas ao sistema socioeducativo, respondeu que, atualmente, os que se encontram nesta unidade, cerca de $80 \%$, 
são oriundos de outras cidades como Rondonópolis, Cuiabá, Cáceres, Lucas do Rio Verde etc. e, isso dificulta as visitas dos pais e/ou responsáveis.

É importante realçar que essa pesquisa foi realizada, também, em um dia de visita e que nenhum familiar compareceu. Foi informado que, muito raramente, as pessoas da família comparecem para visitação.

Em se tratando das alianças com a sociedade, de modo geral, comunicou que as parcerias firmadas com a sociedade e órgãos governamentais buscam promover melhor atendimento para os adolescentes. Há, inclusive, parceria com a Defensoria Pública e com o Ministério Público, que vêm atendendo sempre, prontamente, quando solicitados. Ressalta a importância da mídia, no que se refere a divulgação dos resultados positivos apresentados. Nesse aspecto, o profissional diz que é muito benéfico, a julgar que estes adolescentes são membros da sociedade e, portanto, esta deve auxiliar nesse processo de ressocialização.

Tal colocação vai ao encontro do que preconiza o Sistema Nacional de Atendimento Socioeducativo - SINASE, de que não se deve internar os adolescentes e fazer com que cumpram a medida de portas fechadas, mas, sim, deve existir em vínculo entre a sociedade no que concerne à saúde, educação e etc. Nesse sentido, o município, por meio de universidades e a prefeitura local, vem oferecendo algumas contribuições.

Ao findar essa etapa do estudo, ambos os entrevistados reafirmaram o seu posicionamento de que, a maioria dos casos que chegam à esta instituição, são provenientes de lares desestruturados. Portanto, ratificam que há relação entre desestrutura familiar e adolescentes em conflito com a lei, observando as peculiaridades de cada família. Apontaram que as mudanças da dinâmica familiar e o consumismo exacerbado, a inversão de valores éticos, juntamente com o uso de drogas lícitas e ilícitas, podem promover desequilíbrio nas relações familiares e, por consequência, conduzir os seus para o mundo marginal.

Neste diapasão entende-se ser imprescindível que o Estado promova, por meio de uma rede de apoio, o acompanhamento das famílias que possuem um dos seus envolvidos em atos infracionais, bem como qualquer família que se encontre em situação de vulnerabilidade, na qual o alcoolismo, a violência e o uso de drogas estejam presentes. Essa prática é condição singular não só para prevenção de ações ilícitas, mas para ressocialização dos adolescentes que já sofrem a intervenção do poder judiciário, por meio das medidas socioeducativas, e, posteriormente, deverá retornar ao seio familiar. Acredita-se que é preciso buscar a raiz do problema, para que, de fato, haja a reinserção social. 


\section{CONCLUSÃO}

Em tempos contemporâneos, na qual é possível notar o grande número de adolescentes envolvidos em práticas ilícitas, a família passa a ser peça chave, na busca por respostas à essa problemática.

Observa-se que as mudanças mais significativas na dinâmica familiar ocorreram, em grande parte, pela democratização da informação, pela inserção da mulher no mercado de trabalho, dentre outros fatores. Tais mudanças, em alguns casos, promoveram situações que resultaram em comportamentos antissociais graves praticados por adolescentes e que, por vezes, são resolvidos na esfera judiciária.

Partindo dessa premissa, a hipótese inicial deste trabalho se confirma, uma vez que a desestruturação familiar foi elemento quase que unânime, para a condução de ações infracionais, seja para o uso de drogas, seja para infrações mais graves, ou para o abandono escolar. Tal fato foi constatado, não só na pesquisas junto aos adolescentes internos, no sistema socioeducativo, do município de Barra do Garças - MT, mas, também, pelas entrevistas concedidas pelo Psicólogo e pela Assistente Social que atuam nessa instituição.

Em análise profícua, verificou-se que o Estado, por sua vez, contribui de forma insípida, considerando que pune os infratores, mas não oferece acompanhamento às suas famílias, assim como, também, não presta acompanhamento adequada aos que se encontram em situação de vulnerabilidade. Com isto, forma-se um processo cíclico, na qual o adolescente sai do sistema socioeducativo e retorna ao seio de uma família que não pode dar o suporte psicológico, moral e, até mesmo financeiro, à este sujeito que, ainda, está em estado de atenção.

Se o ser humano é, também, fruto do meio em que vive, este púbere, ao retornar para um ambiente contaminado por ações inadequadas, tais como violência doméstica, alcoolismo, drogadição, ou um ambiente na qual os vínculos afetivos, ainda, não foram consolidados, a ponto de se apoiarem mutuamente, a reincidência é quase certa. Sendo assim, intervir nesse cenário é condição sine qua non para se ter uma sociedade saudável.

Nesse diapasão, é primordial que o Estado busque mecanismos para resolver a raiz do problema, por meio, principalmente, da garantia dos direitos fundamentais: educação de qualidade, atendimento à saúde eficaz, moradia digna, emprego, acompanhamento psicológico 
às famílias que apresentam fragilidades. Trata-se, portanto, da realização de um trabalho preventivo.

Infelizmente, o que se observa na realidade brasileira é que os direitos, em grande parte, são negados pelo Estado, que se mostra incapaz para atender tais demandas. Em contrapartida, a sociedade se encontra em clima de pânico, pois a cada dia a mídia apresenta atos violentos cometidas por adolescentes e, a sensação de impunidade, predomina, de modo geral.

Nessa conjuntura, faz-se necessário que família, Estado e sociedade se unam em favor de um bem maior, que é a sua ressocialização, assim como se tornem parceiros para realizarem atividades preventivas e/ou restauradoras junto às famílias.

Acredita-se que se o adolescente encontrar no seio familiar condições dignas, ambiente harmonioso, afeto, respeito ao outro, regras de convivência, direcionamento acerca de valores morais e éticos, poderá ter conduta salutar para a vida em coletividade, o que favorecerá a todos e tornará a sociedade mais justa e democrática. Esse, ainda, é o maior desafio desse século.

\section{REFERÊNCIAS}

ASSIS, Simone Gonçalves de; CONSTANTINO, Patrícia. Filhas do Mundo: Infração Feminina no Rio de Janeiro, $1^{\text {a }}$ ed. Rio de Janeiro: Fio Cruz, 2001.

BRASIL. Lei $n^{\circ} 8069$ de 13 de Julho de 1990. Dispõe sobre o Estatuto da Criança e do Adolescentes e dá outras providencias. Brasília, DF, de 13 Jul. de 1990, Disponível em: <http://www.planalto.gov.br/ccivil_03/leis//8069.htm> Acesso em: 18 jul. 2014. . Constituição da República Federativa do Brasil. Brasília: Senado, 1988.

. Lei $n^{\circ} 6515$ de 26 de Dezembro de 1977. Regula os casos de dissolução da sociedade conjugal e do casamento, seus efeitos e respectivos processos, e dá outras providências. Brasília, DF, 26 de Dez. de 1977. Disponível em:

<http://www.planalto.gov.br/ccivil_03/leis/l6515.htm>. Acesso em: 20 set. 2014.

. Lei n ${ }^{\circ} 4121$ de 27 de Agosto de 1962. Dispõe sobre a situação Jurídica da mulher casada. Diário Oficial da República Federativa do Brasil. Brasília, DF, 27 ago. 1962. Disponível 
A DESESTRUTURAÇÃO FAMILIAR E O ADOLESCENTE EM CONFLITO COM A LEI: PONTOS E CONTRAPONTOS

em: <http://www.planalto.gov.br/ccivil_03/leis/1950-1969/L4121.htm>. Acesso em: 20 set. 2014.

COSTA, Florença Ávila de Oliveira e MARRA, Marlene Magnabosco.Famílias brasileiras chefiadas por mulheres pobres e monoparentalidade feminina: risco e proteção. Rev. bras. psicodrama[online]. 2013, vol.21, n.1, pp. 141-153. Disponível em< http: / / pepsic.bvsalud.org/scielo.php?script=sci_arttext\&pid=S0104-53932013000100011. Acesso fev. 2016

DALLO, Luana e MARTINS, Raul Aragão Martins. Uso de álcool entre adolescentes escolares: um estudo-piloto. (2011) http://www.scielo.br/pdf/paideia/v21n50/05.pdf. Acesso maio 2016.

DIAS, Maria Berenice. A evolução da família e seus direitos. Disponível em http://www.mariaberenice.com.br/uploads/7_a_evolu\%E7\%E3o_da_fam\%EDlia_e_seus_direitos. pdf. Acesso em maio 2016

. Manual do Direito das Famílias. 2. ed. Porto Alegre: Livraria do Advogado, 2005.

DONIZETTI, Elpídio; QUINTELLA, Felipe. Curso didático de direito civil. 3.ed. São Paulo: Atlas, 2014.

FACUNDES, Márcia Botelho. Aprendendo valores éticos. 4 ed. Belo Horizonte: Autêntica, 2001.

FILHO, Antônio Nery; TORRES, Inês Maria Antunes Paes (orgs.). Drogas isso lhe interessa?

Confira Aqui. Salvador, BA: CETAD/ UFBA/ CPTT/ PMV, 2002.

GONÇALVES, Carlos Roberto. Direito Civil Brasileiro, Direito de Família. Vol. 06. 9a ed. São Paulo: Saraiva, 2012.

KONZEN, Afonso Armando. Pertinência socioeducativa: reflexões sobre a natureza jurídica das medidas. Porto Alegre: Livraria do Advogado, 2005.

MALUF, Adriana Caldas do Rego Freitas Dabus. Novas modalidades de Família na Pós Modernidade. São Paulo: Atlas, 2010.

NAPLAVA, Thomas; OBERWITTLER, Dietrich. Factores familiares e delinquência juvenil: resultados da investigação sociológica na Alemanha. In: FONSECA, António Castro.

Comportamento antissocial e família. Coimbra: Almedina, 2002.

RESENDE, Gisele Silva Lira de. A Educação a as Novas Configurações Familiares. Rev. FACISA ON LINE. v. 1, n. 2 (2012). Disponível em <

http://periodicos.faculdadecathedral.edu.br/revistafacisa/article/view/17. Acesso maio 2016.

ROUSSEAU, Jean-Jacques. Do Contrato Social França, 1762. p.11. Disponível em:

<http://www.ebooksbrasil.org/adobeebook/contratosocial.pdf>Acesso em 15 set. 2014. 
SAPIENZA, Graziela e PEDREMONICO, Márcia Regina Marcondes. (2005). Risco, proteção e resiliência no desenvolvimento da criança e do adolescente [Versão eletrônica]. Psicologia em Estudo, 10(2), 209-216. Recuperado em 19 setembro 2009, de

http://www.scielo.br/pdf/pe/v10n2/v10n2a07.pdf. Acesso maio. 16.

SCIVOLETTO, Sandra, e GIUSTI, L. S. (2007). Fatores protetores e de risco associados ao uso de drogas na adolescência [Versão eletrônica]. Álcool e drogas sem distorção.

http://apps.einstein.br/alcooledrogas/novosite/atualizacoes/ac_131.htm Acesso maio

SOUZA, Jadir Ciqueira de. A afetividade dos direitos da criança e do adolescente. São Paulo: Editora Pillares, 2008.

VENOSA, Silvio de Salvo. Direito civil: direito de família. 9a ed. Vol. 06 São Paulo: Atlas, 2009.

VYGOTSKY, Lev. Semiovich. A formação social da mente. São Paulo: Martins Fontes, 1998.

Recebido em: 22.04.2016 / Revisões requeridas em: 25.05.2016 / Aprovado em: 17.06.2016 